\title{
AS COMPETÊNCIAS DO ENFERMEIRO FRENTE AO SERVIÇO DE ATENDIMENTO MÓVEL DE URGÊNCIA - SAMU
}

\section{REVISÃO INTEGRATIVA}

REIS, Adilson dos ${ }^{1}$

EVARISTO, Leidiane da Silva ${ }^{2}$

SOUSA, Clarisse Cristina Ferreira Silva ${ }^{3}$

CASTRO, Mônica França de ${ }^{4}$

GUASTALDI, Rosimeire ${ }^{5}$

REIS, Adilson dos. Et al. As competências do enfermeiro frente ao serviço de atendimento móvel de urgência - SAMU. Revista Científica Multidisciplinar Núcleo do Conhecimento. Ano 04, Ed. 11, Vol. 04, pp. 159-170. Novembro de 2019. ISSN: 2448-0959, Link de

acesso: https://www.nucleodoconhecimento.com.br/saude/competencias-doenfermeiro

\section{RESUMO}

Introdução: No Brasil, as redes de atenção de urgência e emergência são amparadas e regulamentadas pelo sistema único de saúde, o profissional de enfermagem

\footnotetext{
1 Graduando em Enfermagem.

2 Graduanda em Enfermagem.

${ }^{3}$ Graduanda em Enfermagem.

${ }^{4}$ Graduanda em Enfermagem.

${ }^{5}$ Doutorado em andamento em Ciências da saúde. Mestrado em Ciências da Saúde. Especialização em Gerenciamento de Serviços de Enfermagem. Graduação em Enfermagem.
} 
é essencial para as práticas do atendimento realizado pelos serviços de atendimento móvel de urgência (SAMU), não somente no que tange a orientação e apoio médico, nota-se que a enfermagem tem um grande quantitativo de funções relacionadas ao seu atendimento no SAMU. Objetivos: Identificar o trabalho do Enfermeiro frente ao Serviço de Atendimento Móvel de Urgência. Método: Foi realizada uma pesquisa do tipo revisão sistemática da literatura, com análise dos principais periódicos de enfermagem nas bases de dados Scientific Eletronic Library Online (SciELO), Literatura Latino-Americana e do Caribe em Ciências da Saúde (Lilacs) e o Sistema Online de Busca e Análise de Literatura Médica (Pubmed/MEDLINE). Foram levantados um total de 47 artigos com a temática do estudo. Resultados: Foi evidenciado que há uma quantidade considerável de artigos relacionados às competências do enfermeiro frente ao SAMU, e a relevância da profissão para o bom funcionamento do SAMU. Conclusão: Conclui-se que mediante ao desenvolvimento científico e técnico da profissão, com a realização de cursos de graduação e pós-graduação, considera-se importante as atribuições de enfermagem frente ao SAMU, mas que ainda é necessário novas pesquisas por estudantes desta categoria.

Palavras-chave: Enfermagem, Serviço de Atendimento Móvel de Urgência, atribuições de enfermagem.

\section{INTRODUÇÃO}

No Brasil as redes de atenção de urgência e emergência são amparadas e regulamentadas pelo sistema único de saúde, pela portaria n 1.600, de 2011. E são estabelecidas pelos segmentos de: promoção, prevenção e vigilância a saúde, além dos serviços de atendimento móvel de urgência (SAMU). O enfermeiro é o profissional com formação científica e competência humana para lidar com a vida, e seu papel é de suma importância para atendimentos que necessitam de procedimentos invasivos em casos que envolvam as unidades de suporte avançado de vida (SAV). ${ }^{1}$

A enfermagem é uma ciência ampla que contempla os direitos humanos e da saúde, com olhar humanizado no que tange ao desenvolvimento humano e cada vez mais 
conquista seu espaço nos mais diversos setores de saúde. Antigamente, o profissional de enfermagem era visto como um profissional auxiliar do médico, hoje entende-se essa profissão com amplitude, que tem diversas contribuições que favorecem os pacientes, seja sobre informações, procedimento, manuseio de equipamentos e humanização. ${ }^{2}$

O profissional de enfermagem é essencial para as práticas do atendimento realizado pelo SAMU, não somente no que tange a orientação e apoio médico, mas também no atendimento humanizado, com ampla visão de organização, gerenciamento de equipe, conhecimento de equipamentos e manobras que salvam vidas. Portanto, é possível que o enfermeiro foque constantemente em formação continuada, para que se torne cada vez mais especializado na prestação de Primeiros Socorros, para desenvolver o seu trabalho com qualidade e efetividade. ${ }^{3}$

Segundo Costa 2016, a atuação do enfermeiro no atendimento pré-hospitalar móvel deve ser ampliada, por se tratar de um campo extremamente importante em prol da vida e quanto mais eficiente for esse atendimento, maior a chance de vida de um indivíduo. Em conformidade, para Mendes 2010, o Serviço de Atendimento Móvel de Urgência - SAMU representa um atendimento crucial para o indivíduo que passa por alguma intercorrência de saúde, e precisa ser atendido por profissionais aptos e capazes de realizarem todos os procedimentos necessários, visando a preservação da vida $^{3}$

A qualidade dos serviços de saúde oferecidos no Brasil na década de 1980 passou por mudanças significativas, impulsionadas pela falta de recursos financeiros evidenciando a importância de adotar uma nova forma de administrar e gerenciar os recursos financeiros. O gerenciamento de qualidade feito pela enfermagem representa grande importância, portanto é entendido como uma estratégia que alcança um aceitável padrão contínuo de assistência com qualidade. O gerenciamento permite o desenvolvimento de recursos humanos gerando responsabilidades à equipe, incluindo gerentes e administradores. ${ }^{4}$ 
Reconhecendo que o Enfermeiro é indispensável na realização do atendimento préhospitalar, torna-se de grande interesse compreender as competências e as contribuições para a área, surgindo a indagação: qual as atribuições do enfermeiro frente ao atendimento no SAMU?

\section{REFERENCIAL TEÓRICO}

A alta demanda por serviços eficazes de atendimento às urgências e emergências médicas gerou diversos modelos de sistemas de atendimento em todo o mundo. No Brasil, a primeira proposta aconteceu em 2003, através da Política Nacional de Atenções às Urgências - (PNAU). ${ }^{5}$

De acordo com Mendes 2010, esta política representa o esforço do Ministério da Saúde em organizar os fluxos regionais de atenção integral para os casos de urgência e emergência no Brasil. Dessa forma, a PNAU norteia-se pelos princípios do SUS e é estruturada em cinco eixos, sendo estes: promoção da qualidade de vida; organização em rede; operação de centrais de regulação; capacitação e educação continuada; humanização da atenção. ${ }^{6}$

Sua implementação foi marcada pelo componente pré-hospitalar móvel, apresentando-se como uma estratégia no Serviço de Atendimento Móvel de Urgência (SAMU), constituindo um modelo padronizado de assistência, na qual o atendimento é prestado após uma chamada gratuita para o número 192, e a central médica define como deve ser conduzido o atendimento. ${ }^{6}$

Além disso, houve uma ampliação de acesso aos serviços, não só através do atendimento prestado pelo SAMU, bem como a implementação das Unidades de Pronto Atendimento (UPA), que se apresentam como a estratégia mais recente da política, unindo a estratégia de capacitação e educação continuada dos profissionais, denominada Núcleos e Educação e Urgência. ${ }^{6}$ 


\section{RESULTADOS}

Buscando compreender a importância do enfermeiro frente ao serviço móvel de urgência (SAMU), durante o levantamento de dados, levando em consideração os critérios de inclusão e exclusão, foram encontrados 9 artigos científicos que abordaram as competências assistenciais e gerenciais do enfermeiro em publicações apresentadas nas tabelas no item anterior, em duas etapas, a primeira diz sobre a caracterização dos artigos publicados quanto à título, local, autor, ano, tipo de estudo e objetivo e a segunda quanto as competências e atividades relacionadas e porcentagem.

A coleta de dados desta revisão integrativa resultou através da seleção dos estudos descritos no quadro 1

Quadro 1 - Caracterização dos artigos publicados quanto à título, local, autor, ano, tipo de estudo e objetivo. São Paulo, 2019

\begin{tabular}{|c|c|c|c|c|}
\hline Identificação & Título, autor & Local, ano & $\begin{array}{l}\text { Tipo de } \\
\text { estudo }\end{array}$ & Objetivo \\
\hline A1 & $\begin{array}{l}\text { Enfermeiros do } \\
\text { serviço de } \\
\text { atendimento } \\
\text { móvel de } \\
\text { urgência: perfil e } \\
\text { atividades } \\
\text { desenvolvidas. } \\
\text { Luchtemberg MN, } \\
\text { Pires DEP }\end{array}$ & $\begin{array}{l}\text { Florianópolis, } \\
2015\end{array}$ & $\begin{array}{l}\text { Estudo } \\
\text { descritivo } \\
\text { qualitativo }\end{array}$ & $\begin{array}{l}\text { Caracterizar o } \\
\text { perfil e identificar } \\
\text { as atividades } \\
\text { desenvolvidas } \\
\text { por enfermeiros } \\
\text { do serviço de } \\
\text { atendimento } \\
\text { móvel de } \\
\text { urgência de um } \\
\text { estado da região } \\
\text { sul do Brasil }\end{array}$ \\
\hline A2 & $\begin{array}{l}\text { Educação } \\
\text { permanente }\end{array}$ & $\begin{array}{l}\text { São Paulo, } \\
2013\end{array}$ & $\begin{array}{l}\text { Estudo } \\
\text { qualitativo }\end{array}$ & $\begin{array}{l}\text { O estudo } \\
\text { objetivou analisar }\end{array}$ \\
\hline
\end{tabular}




\begin{tabular}{|c|c|c|c|c|}
\hline & $\begin{array}{l}\text { continuada como } \\
\text { estratégias de } \\
\text { gestão no serviço } \\
\text { de atendimento } \\
\text { móvel de } \\
\text { urgência. Hetti } \\
\text { LBE, Bernardes A, } \\
\text { Gabriel CS, } \\
\text { Fortuna CM, } \\
\text { Maziero VG. }\end{array}$ & & & $\begin{array}{l}\text { a percepção dos } \\
\text { profissionais } \\
\text { sobre educação } \\
\text { permanente e/ou } \\
\text { continuada no } \\
\text { Serviço } \\
\text { Atendimento } \\
\text { Móvel } \\
\text { Urgência de um } \\
\text { município do } \\
\text { Estado de São } \\
\text { Paulo }\end{array}$ \\
\hline A3 & $\begin{array}{lr}\text { A visão do } \\
\text { enfermeiro/ gestor } \\
\text { sobre as } \\
\text { necessidades de } \\
\text { implementar apoio } \\
\text { psicológico aos } \\
\text { profissionais do } \\
\text { serviço de } \\
\text { atendimento } \\
\text { móvel de } \\
\text { urgência; Meskita } \\
\text { KL, Gomes GPLA, } \\
\text { Silva MJBF, } \\
\text { Santos LF. }\end{array}$ & $\begin{array}{l}\text { Tocantins, } \\
2014 .\end{array}$ & $\begin{array}{l}\text { Pesquisa } \\
\text { descritiva e } \\
\text { exploratória } \\
\text { qualitativa }\end{array}$ & $\begin{array}{l}\text { Analisar a visão } \\
\text { do enfermeiro/ge } \\
\text { sor sobre } \\
\text { necessidade de } \\
\text { implementar o } \\
\text { apoio psicológico } \\
\text { aos profissionais } \\
\text { do SAMU }\end{array}$ \\
\hline A4 & $\begin{array}{l}\text { O cotidiano dos } \\
\text { enfermeiros que } \\
\text { atuam no serviço } \\
\text { de atendimento } \\
\text { móvel de }\end{array}$ & $\begin{array}{l}\text { Minas } \\
\text { Gerais, } 2017\end{array}$ & $\begin{array}{l}\text { Pesquisa } \\
\text { qualitativa e } \\
\text { exploratória }\end{array}$ & $\begin{array}{l}\text { Compreender o } \\
\text { cotidiano de } \\
\text { trabalho dos } \\
\text { enfermeiros que } \\
\text { atuam no Serviço }\end{array}$ \\
\hline
\end{tabular}




\begin{tabular}{|c|c|c|c|c|}
\hline & $\begin{array}{l}\text { urgência. Tavares } \\
\text { TY, Santana JCB, } \\
\text { Eloy MD, Oliveira } \\
\text { RD, Paula RF }\end{array}$ & & & $\begin{array}{l}\text { de Atendimento } \\
\text { Móvel de } \\
\text { Urgência }\end{array}$ \\
\hline A5 & $\begin{array}{l}\text { Perspectivas de } \\
\text { enfermeiras no } \\
\text { cuidado em } \\
\text { atendimento pré- } \\
\text { hospitalar móvel. } \\
\text { Anjos MS, Oliveira } \\
\text { SS, Rosa DOS }\end{array}$ & Bahia, 2016 & $\begin{array}{l}\text { Estudo } \\
\text { exploratório } \\
\text { qualitativo }\end{array}$ & $\begin{array}{l}\text { Descrever as } \\
\text { perspectivas das } \\
\text { enfermeiras no } \\
\text { cuidado em } \\
\text { atendimento pré- } \\
\text { hospitalar móvel. }\end{array}$ \\
\hline A6 & $\begin{array}{l}\text { Atuação do } \\
\text { enfermeiro no } \\
\text { atendimento pré- } \\
\text { hospitalar móvel. } \\
\text { Adão RS, Santos } \\
\text { MR. }\end{array}$ & $\begin{array}{l}\text { São Paulo, } \\
2013\end{array}$ & $\begin{array}{l}\text { Revisão } \\
\text { bibliográfica } \\
\text { qualitativa }\end{array}$ & $\begin{array}{l}\text { O objetivo com } \\
\text { este estudo foi } \\
\text { descrever as } \\
\text { ações do } \\
\text { enfermeiro em } \\
\text { unidade básica e } \\
\text { avançada de } \\
\text { saúde no APH } \\
\text { móvel, por meio } \\
\text { de revisão } \\
\text { literária. }\end{array}$ \\
\hline A7 & $\begin{array}{l}\text { Atuação do } \\
\text { enfermeiro de um } \\
\text { serviço de } \\
\text { atendimento pré- } \\
\text { hospitalar privado. } \\
\text { Peres PSQ, Arboit } \\
\text { EL, Camponogara } \\
\text { S, Pilau COB, }\end{array}$ & $\begin{array}{l}\text { Rio Grande } \\
\text { do Sul, } 2018\end{array}$ & $\begin{array}{l}\text { Estudo } \\
\text { descritivo } \\
\text { exploratório } \\
\text { qualitativo }\end{array}$ & $\begin{array}{l}\text { Conhecer a } \\
\text { percepção de } \\
\text { trabalhadores de } \\
\text { saúde sobre a } \\
\text { atuação do } \\
\text { enfermeiro em } \\
\text { um serviço de } \\
\text { atendimento pré- } \\
\text { hospitalar. }\end{array}$ \\
\hline
\end{tabular}




\begin{tabular}{|c|c|c|c|c|}
\hline & $\begin{array}{l}\text { Menezes OS, } \\
\text { Kaefer CT. }\end{array}$ & & & \\
\hline A8 & $\begin{array}{l}\text { Atuação do } \\
\text { Enfermeiro no } \\
\text { Atendimento Pré- } \\
\text { hospitalar móvel. } \\
\text { Fernandez MG, } \\
\text { Espindula BM. }\end{array}$ & $\begin{array}{l}\text { São Paulo, } \\
2018\end{array}$ & $\begin{array}{l}\text { Revisão } \\
\text { integrativa } \\
\text { da literatura }\end{array}$ & $\begin{array}{l}\text { O objetivo com } \\
\text { este estudo foi } \\
\text { descrever as } \\
\text { ações do } \\
\text { enfermeiro em } \\
\text { unidade básica e } \\
\text { avançada de } \\
\text { saúde no APH } \\
\text { móvel, por meio } \\
\text { de revisão } \\
\text { literária. }\end{array}$ \\
\hline A9 & $\begin{array}{l}\text { Supervisão do } \\
\text { enfermeiro no } \\
\text { atendimento pré- } \\
\text { hospitalar móvel. } \\
\text { Bernardes A, } \\
\text { Maziero GV, Hetti } \\
\text { LBE, Baldin MSC, } \\
\text { Gabriel CS. }\end{array}$ & $\begin{array}{l}\text { São Paulo, } \\
2014\end{array}$ & $\begin{array}{l}\text { Pesquisa } \\
\text { descritiva } \\
\text { qualitativa }\end{array}$ & $\begin{array}{l}\text { estudo } \\
\text { objetivou analisar } \\
\text { como ocorre a } \\
\text { supervisão no } \\
\text { Serviço de } \\
\text { Atendimento } \\
\text { Móvel } \\
\text { Urgência (SAMU) } \\
\text { de um município } \\
\text { do Estado de São } \\
\text { Paulo }\end{array}$ \\
\hline
\end{tabular}

Fonte: Reis, 2019.

Os estudos selecionados foram analisados e agrupados conforme competências encontradas, atividades e porcentagem, descritas no quadro 2. 
Quadro 2: Distribuição dos artigos encontrados quanto as competências assistenciais e gerenciais. São Paulo, 2019

\begin{tabular}{|c|c|c|c|}
\hline TIPO & ARTIGOS & ATIVIDADES & $\%$ \\
\hline Assistenciais & $\begin{array}{l}\text { A1 } \\
\text { A4 } \\
\text { A5 } \\
\text { A6 } \\
\text { A7 } \\
\text { A8 }\end{array}$ & $\begin{array}{l}\text { - Avaliação ao agravo e } \text { tratamento; } \\
\text { - Medicação conforme prescrição médica; } \\
\text { - Punção de acesso venoso, sondagem } \\
\text { vesical } \\
\text { - Monitorização cardíaca e oximetria de pulso; } \\
\text { - Avaliação hemodinâmica, cuidados com a } \\
\text { ventilação } \\
\text { - Curativos; }\end{array}$ & $66,6 \%$ \\
\hline Gerenciais & $\begin{array}{l}\text { A2 } \\
\text { A3 } \\
\text { A9 }\end{array}$ & $\begin{array}{l}\text { - Atividades de gerenciamento e/ou atividades } \\
\text { administrativas; } \\
\text { - Realizar capacitações e educação } \\
\text { permanente; } \\
\text { - Construir } \\
\text { - Supervisionar e avaliar as ações da equipe } \\
\text { no APH } \\
\text { - Preenchimento da ficha de ocorrência; } \\
\text { - Check list dos materiais, medicamentos e } \\
\text { equipamentos; } \\
\text { - Relatório em livro ata, inventário da base e } \\
\text { controle de estoque, relatório de enfermagem, } \\
\text { pedido de medicamentos e materiais; } \\
\text { - Desinfecção de equipamentos e viatura; } \\
\text { - Ficha de medicamentos controlados, termo } \\
\text { de responsabilidade de transferência, controle } \\
\text { de temperatura do almoxarifado; } \\
\text { - Escala de desinfecção da viatura, } \\
\text { preenchimento de prontuário, participação em } \\
\text { elaboração de projetos como o educa SAMU; }\end{array}$ & $33,3 \%$ \\
\hline
\end{tabular}


- Participação de reuniões e preenchimento da folha de ponto

TOTAL:

Fonte: Reis, 2019

\section{DISCUSSÃO}

Para melhor compreensão dos resultados, eles serão discutidos em dois tópicos: competências assistenciais para atuação do enfermeiro no SAMU e competências gerenciais para atuação do enfermeiro no SAMU.

\section{COMPETÊNCIAS ASSISTENCIAIS DO ENFERMEIRO PARA ATUAÇÃO NO SAMU}

As publicações abordaram as competências do enfermeiro, tanto as assistenciais como as gerenciais concomitantemente, porém $33 \%(n=3)$ das publicações o foco principal era a atuação do enfermeiro enquanto gestor, dentre as competências assistenciais encontradas, as que mais se destacam e são recorrentes são: avaliação da extensão dos agravos dando prioridade ao maior comprometimento e realização de procedimentos e cuidados. Destacando-se entre os procedimentos, a punção venosa, a passagem de sonda vesical de demora e sondagem nasogástrica, enquanto que na prestação de cuidados se encontrou: realização de curativos, monitorização dos sinais vitais e administração de medicamentos, monitorização cardíaca e oximetria de pulso, higiene e conforto, avaliação hemodinâmica, imobilizações, anamnese, auxílio ao médico nos procedimentos, como a reanimação e tomada de decisões. ${ }^{6}$

Entre outros. Diante das múltiplas funções exercidas pelo enfermeiro, é clara a ideia da importância do mesmo e da responsabilidade que Ihe é dada, o que requer o desenvolvimento de habilidades que envolvam a cognição, atitudes e a realização dos procedimentos, o que finda por implicar na função de gestor, significando em muitos casos, o surgimento de desgaste físico e mental. Portanto é imprescindível a 
disponibilização dos recursos humanos e físicos com o intuito de prestar o melhor atendimento à vítima, sempre objetivando a minimização dos agravos.

\section{COMPETÊNCIAS GERENCIAIS DO ENFERMEIRO PARA ATUAÇÃO NO SAMU}

Para as competências gerenciais principais evidenciou-se que, é papel do enfermeiro a elaboração de protocolos para a correta prestação dos cuidados, considerando toda a casuística que justifica o atendimento e o comprometimento do paciente. ${ }^{8}$ Cabendo também ao enfermeiro, o preenchimento da ficha de ocorrência do atendimento, checagem e reposição do estoque de materiais que devem estar no veículo e que são pertinentes ao atendimento, desinfecção dos equipamentos e do veículo, relatório de enfermagem, participação ou elaboração de projetos que possibilitem a educação em saúde de forma permanente. ${ }^{9}$

Visto a evidenciação das competências do enfermeiro, entende-se a importância e que este profissional é indispensável considerando tanto as atividades assistenciais e gerenciais, que são privativas do enfermeiro, como, prestar suporte aos colaboradores da equipe de enfermagem, o que acarreta no índice de qualidade da prestação do atendimento entendendo que a não realização, o não conhecimento das suas atividades pertinentes podem caracterizar danos ou morte a vítima atendida. ${ }^{9}$

Visando além de tudo, a boa qualidade da assistência de enfermagem, cabe privativamente ao enfermeiro a gerencia da equipe de enfermagem, devendo o mesmo ser responsável pelo dimensionamento da equipe, considerando a performance de cada colaborador, a elaboração de protocolos que baseados em evidencias cientificas e adaptado a realidade da saúde brasileira, forneçam meios de realizar o atendimento e que respalde as ações do profissional. ${ }^{10}$ Segundo Santos e Adão, 2013 a introdução do profissional Enfermeiro no atendimento pré-hospitalar móvel se deu através da PNAU, o que entra em concordância com o que diz o Conselho Regional de Enfermagem, que considera este profissional importante para a composição da equipe do APH, visto que o mesmo é capaz de desenvolver ações 
com o intuito de preservar e reduzir danos à vida, seja por meio da assistência direta ou pela gestão da equipe. ${ }^{10}$

Enquanto gestor, uma das mais importantes competências de responsabilidade do Enfermeiro é a educação permanente em saúde, visto que o mesmo é detentor de conhecimento teórico e científico. Essa educação em saúde se traduz mais rotineiramente pelas orientações e explicações passadas à família da vítima do que propriamente aos colaboradores de enfermagem, onde o enfermeiro é responsável pelo treinamento e capacitação de seus colaboradores, visando uma melhor qualidade dos serviços prestados. ${ }^{1,10}$

\section{CONCLUSÃO}

Dos 9 artigos identificados para alcançar os objetivos propostos, $100 \% \quad(n=9)$ abordaram as competências assistenciais, porém deste total, apenas 33\% $(n=3)$ abordaram as competências gerenciais da categoria de enfermagem. Para as competências gerenciais, as que mais se destacaram foram as que tem relação direta com a vítima, como a prestação dos cuidados. Enquanto as gerenciais encontraramse competências que não estão ligadas diretamente a vítima, ficando as atividades administrativas como as principais, como exemplo, o dimensionamento de equipe. Conclui-se que o enfermeiro é um profissional indispensável tanto no atendimento direto a vítima quanto nas ações que coordenam esse atendimento.

\section{REFERENCIAS}

1. LUCHTEMBERG, Marilene Nonnemacher; PIRES, Denise Elvira Pires de. Enfermeros del Servicio de Atención Móvil de Urgencia: perfil y actividades desarrolladas. Revista Brasileira de Enfermagem, v. 69, n. 2, p. 213-220, 2016.

2. ADÃO, Rodrigo de Souza; SANTOS, Maria Regina dos. Atuação do enfermeiro no atendimento pré-hospitalar móvel. Revista Mineira de Enfermagem, v. 16, n. 4, p. 601-608, 2012. 
3. BERNARDES, Andrea et al. Supervisão do enfermeiro no atendimento préhospitalar móvel. Revista Eletrônica de Enfermagem, v. 16, n. 3, p. 635-43, 2014.

4. BRASIL, Ministério da Saúde. Política Nacional de Atenção às Urgências. Brasília, Editora do Ministério da Saúde, 3. ed. ampl., 2006.

5. COSTA, Gabriela. Uma abordagem da atuação história da Enfermagem em face das políticas de saúde. Revista Mineira de Enfermagem - REME; vol 10.4; João Pessoa - PB, 2016

6. EL HETTI, Livia Barrionuevo et al. Educação permanente/continuada como estratégias de gestão no Serviço de Atendimento Móvel de Urgência. Revista Eletrônica de Enfermagem, v. 15, n. 4, p. 973-82, 2013.

7. MENDES, Eugênio Vilaça. As redes de atenção à saúde. Ciênc. saúde coletiva, Rio de Janeiro, v. 15, n. 5, p. 2297-2305, Aug. 2010.

8. MESQUITA, Kayena Lopes et al. A visão do enfermeiro/gestor sobre a necessidade de implementar apoio psicológico aos profissionais do serviço de atendimento móvel de urgência. Revista de enfermagem do centro oeste Mineiro, 2014.

9. NETTINA, Sandra. Prática de Enfermagem. 9aㅡ Ed. Rio de Janeiro: Guanabara Koogan, 2011.

10. PERES, Paulo Sergio Quevedo et al. Atuação do enfermeiro em um serviço de atendimento pré-hospitalar privado/Nurse performance on a private prehospital assistance. Revista de Pesquisa: Cuidado é Fundamental Online, v. 10, n. 2, p. 413-422, 2018.

11. TAVARES, Tayrine Ypuena et al. $\mathbf{O}$ cotidiano dos enfermeiros que atuam no serviço de atendimento móvel de urgência. Revista de Enfermagem do Centro Oeste Mineiro, v. 7, 2017.

Enviado: Novembro, 2019.

Aprovado: Novembro, 2019. 